BIOFARM

Jurnal Ilmiah Pertanian

ISSN Print: 0216-5430; ISSN Online: 2301-6442

Vol. 15, No. 1, April 2019

\title{
Analisis Perbedaan Hasil dan Pendapatan Usaha Jamur Tiram (Pleurotus Ostreatus) antara Penggunaan Bran dengan Tepung Jagung (Studi Kasus di Kecamatan Limpung Kabupaten Batang)
}

\author{
Analysis of Differences in Results and Revenue of Oyster Mushroom (Pleurotus \\ Ostreatus) Efforts Between Using Bran with Corn Flour (Case Study in Limpung \\ Sub-district of Batang Regency)
}

Kristiyanto ${ }^{1 *}$

${ }^{1}$ Program Studi Agroteknologi, Fakultas Pertanian, Universitas Pekalongan

*Korespondensi Penulis: kristiyantotiyan@gmail.com

\begin{abstract}
ABSTRAK
Budidaya jamur dapat dilakukan dengan mudah dan murah karena kandungan komponennya banyak menggunakan limbah, misalkan serbuk kayu dari bekas gergaji dan nutrisi. Penelitian Bertujuan untuk mengetahui Perbedaan pendapatanbudidaya jamur tiram antara penggunaan nutrisi dedak dengan tepung jagung. Metode penelitian ini adalah deskriptif analisis. dengan menggunakan analisis biaya dan pendapatan, analisis kelayakan menggunakan RCR, BEP dan ROI dan Analitik SPSS independent sample t-test. Berdasarkan hasil analisis data, biaya produksi pada media nutrisi tepung jagung adalah Rp 7.381.259,4 lebih besar dari media nutrisi dedak yaitu sebesar $\mathrm{Rp} 6.272 .180,23$. pendapatan dengan media nutrisi tepung jagung sebesar Rp. 10.239.000,0 media nutrisi dedak sebesar Rp. 8.418.823,53. Nilai RCR nutrisi tepung jagung sebesar 1,39 dan nutrisi dedak sebesar 1,34, BEPq tepung jagung sebesar 922,66 sedangkan riilnya 1.279,9 kg. BEP (produksi) dedak sebesar 784,02 sedangkan riilnya 1.052,35 kg. BEP Rp (harga) tepung jagung Rp. 5.767,17/kg dan BEP Rp Dedak Rp 5.960,15/kg sedangkan harga riilny adalah Rp 8.000,-. Nilai ROI sebesar media nutrisi tepung jagung sebesar 0,39\% sedangkan media nutrisi dedak sebesar $0,34 \%$.
\end{abstract}

Kata kunci : Jamur Tiram,pendapatan, kelayakan usaha.

\begin{abstract}
Mushroom cultivation can be done easily and cheaply because the content of its components use a lot of waste, for example wood powder from the former saws and nutrients. Research Aims to determine the difference in oyster mushroom cultivation income between the use of bran and corn meal. This research method is descriptive analysis. using cost and revenue analysis, feasibility analysis using RCR, BEP and ROI and SPSS Analytical independent sample t-test. Based on the results of data analysis, production costs on nutritional medium of corn flour is Rp 7.381.259,4 bigger than bran nutrition media that is equal to $R p$ 6,272,180,23. income with nutrition media of corn flour Rp. 10.239.000,0 nutrition media bran amounting to Rp. $8,418,823,53$. RCR value of corn flour nutrition of 1.39 and bran nutrition of 1.34, BEP(production) corn flour by 922.66 while real 1,279.9 kg. BEP (production) of bran amounted to 784.02 while real $1,052.35 \mathrm{~kg}$. BEP Rp (price) corn flour Rp. 5,767.17 I $\mathrm{kg}$ and BEP Rp Dedak Rp 5,960.15 / kg while the real price is Rp 8.000, -. ROI value of nutrient media of corn flour by 0,39\% while nutrition bran media equal to $0,34 \%$.
\end{abstract}

Keywords: Oyster mushroom, income, business feasibility.

\section{PENDAHULUAN}

Di Indonesia jamur yang paling banyak dikonsumsi adalah jamur tiram dan jamur merang. Kedua jamur ini adalah jamur yang media tumbuhnya berbeda. Apabila dibedakan berdasarkan media tumbuhnya jamur dapat dikelompokkan menjadi dua kelompok yaitu jamur kayu dan jamur kompos. Jamur kayu yang dibudidayakan diantara adalah jamur tiram, kuping, shiitakee, ling zhi dan maitake. Jamur tiram adalah jamur kayu yang paling banyak digemari oleh masyarakat. Selain karena harganya yang relatif murah, jamur tiram juga memiliki rasa yang enak dan memiliki sumber gizi dan mineral yang cukup lengkap untuk memenuhi kebutuhan tubuh sebagai sayuran atau bahkan sebagai cemilan sehat bagi seorang vegetarian (Alex,2011).

Jamur merupakan sumber bahan pangan nabati yang cukup potensial, Bahkan beberapa jenis jamur dari alam sudah lama dibudidayakan manusia sebagai sumber gizi 
(Karim, 2008). Jamur merupakan makanan sehat yang kaya manfaat. Jamur memiliki nilai takaran gizi lengkap dengan harga yang relatif terjangkau. Jamur memiliki keunggulan yang tidak dimiliki sayuran jenis lainnya yakni kandungan gizinya yang tinggi. Bahkan kandungan gizi dalam jamur hampir mengimbangi nutrisi pada daging sapi dan daging ayam (Piryadi, 2013).

Budidaya jamur dapat dilakukan dengan mudah dan murah karena kandungan komponennya banyak menggunakan limbah, misalkan serbuk kayu dari bekas gergaji dan nutrisi. Dua komponen tersebut sebagian besar wilayah Indonesia selalu ada dan berlimpah (Alex, 2011). Kecamatan Limpung merupakan salah satu kecamatan di Kabupaten Batang

Nutrisi sangat dibutuhkan oleh setiap makhluk hidup untuk melangsungkan setiap proses kehidupannya, tak terkecuali jamur tiram. Pada budidaya jamur tiram, jamur memperoleh nutrisi dari serbuk gergaji, dimana serbuk gergaji ini berfungsi sebagai media tempat tumbuh. Bahan serbuk gergaji yang baik dapat diperoleh dari bahan kayu keras karena serbuk gergaji kayu jenis tersebut sangat berpotensi dalam meningkatkan hasil panen.

Kayu keras mengandung selulose dalam jumlah banyak dimana solusose ini sangat dibutuhkan oleh jamur. Beberapa jenis kayu keras yang bisa dimanfaatkan sebagai media tanam antara lain dari kayu sengon, kayu kampung, atau kayu mahoni, media yang baik untuk budidaya jamur tiram adalah serbuk gergaji kayu. Selain serbuk gergaji kayu, media tempat tumbuh juga terdiri dari dedak halus, tepung tapioka, tepung jagung, kompos, kapur dan air.

Dedak dan tepung jagung berfungsi sebagai substrat serta penghasil kalori untuk pertumbuhan jamur. Penggunaan bahan nutrisi tambahan media menjadi permasalahan pada petani yaitu manakah yang lebih efisien dengan produkstifitas baglog yang tinggi untuk menghasilkan jamur tiram segar. maka dari itu peneliti memilih judul "Analisis Perbedaan Hasil Dan Pendapatan Usaha Budidaya Jamur Tiram (Pleurotus Ostreatus) Antara Penggunaan Dedak Dengan Tepung Jagung (Studi Kasus Di Kecamatan Limpung Kabupaten Batang ).

Tujuan penelitian ini adalah untuk mengetahui: Hasil dan Pendapatan usaha budidaya jamur tiram antara penggunaan nutrisi dedak dengan tepung jagung, Kelayakan Usaha budidaya jamur tiram antara penggunaan nutrisi dedak dengan tepung jagung, Perbedaan hasil pendapatan usaha budidaya jamur tiram antara penggunaan nutrisi dedak dengan tepung jagung.

\section{METODE PENELITIAN}

Penelitian dilaksanakan pada Mei September 2017 di Kecamatan Limpung Kabupaten Batang. Penelitian ini merupakan penelitian penjelasan berdasarkan metode deskriptif analisis yaitu menganalisis permasalahan apa adanya dan baru saja berlangsung / ex post facto ( Widarjono, 2005) Teknik pelaksanaan penelitian ini dilakukan dengan study kasus.Pengumpulan data dengan metode observasi ke lapangan dan wawancara kepada para petani jamur tiram berdasarkan kuesioner yang berisikan suatu rangkaian pertanyaan mengenai ekonomi budidaya jamur tiram di Kecamatan Limpung sesuai dengan tujuan penelitian. Penentuan sampel menggunakan teknik Sensussebanyak 33 orang petani jamur tiram.

Analisis data dilakukan dengan tabulasi dan fariabel usaha dalam table yang disesuaikan dengan keperluan. Analisis data yang dilaksanakan meliputi :Analisis Biaya dan Pendapatan, Analisis Kelayakan RCR(revenue cost ratio) BEP(break event point) ROI(return of investmen) dan Analisis Perbedaan pendapatanmenggunakan paired sample T-test dengan bantuan aplikasi spss 16 .

\section{HASIL DAN PEMBAHASAN}

Hasil analisis usahatani budidaya jamur tiram dengan media menggunakan nutrisi tepung jagung dan dedak di Kecamatan Limpung Kabupaten Batang dapat di lihat pada tabel 1.

\section{Biaya Produksi}

Rata-rata biaya produksi dapat dibedakan menjadi biaya tetap yang tidak berubah pada besar kecilnya produksi dan biaya variabel yang besar kecilnya selalu berubah-ubah berhubungan langsung dengan biaya produksi (Mubyarto, 1994). Rata-rata biaya produksi pada usaha budidaya jamur tiram dengan mediamenggunakan nutrisi tepung jagung adalah $\mathrm{Rp}$ 7.381.259,4 lebih besar dari 
Tabel 1. Data analisis usahatani budidaya jamur tiram dengan media menggunakan nutrisi tepung jagung dan dedak di Kecamatan Limpung Kabupaten Batang

\begin{tabular}{|c|c|c|c|}
\hline No. & Uraian & Nutrisi tepung jagung & Nutrisi dedak \\
\hline \multirow[t]{5}{*}{1.} & Biaya Tetap & & \\
\hline & Pajak (Rp) & $148.656,3$ & $116.970,6$ \\
\hline & Penyusutan kumbung ( $R p$ ) & $111.918,4$ & $258.700,98$ \\
\hline & Penyusutan peralatan ( $R p$ ) & $84.300,3$ & $96.123,37$ \\
\hline & Jumlah biaya Tetap ( Rp ) & $344.875,0$ & $471.794,93$ \\
\hline \multirow[t]{14}{*}{2.} & Biaya Variabel & & \\
\hline & Serbuk gergajian ( Rp ) & 193.750 & 202.235 \\
\hline & Tepung jagung (Rp ) & 3.403 .125 & - \\
\hline & Dedak ( Rp ) & - & 2.041 .765 \\
\hline & Kapur mill ( Rp ) & 76.188 & 80.412 \\
\hline & Kapur Dolomit ( Rp ) & 92.100 & 96.494 \\
\hline & Bahan Pelengkap ( Rp ) & & \\
\hline & Plastik ( Rp ) & 496.875 & 495.882 \\
\hline & Ring + tutup ( Rp ) & 567.188 & 562.941 \\
\hline & Kapas ( Rp ) & 13.234 & 13.897 \\
\hline & Bibit ( Rp ) & 627.813 & 624.118 \\
\hline & Bahan bakar ( Rp ) & 395.488 & 390.759 \\
\hline & Tenaga Kerja ( Rp ) & 1.170 .625 & 1.291 .882 \\
\hline & Jumlah biaya variabel ( $R p$ ) & $7.036 .384,4$ & $5.800 .385,3$ \\
\hline 3. & Total biaya ( $R p$ ) & $7.381 .259,4$ & $6.272 .180,23$ \\
\hline \multirow[t]{4}{*}{4.} & Pendapatan & & \\
\hline & Volume produksi ( kg ) & $1.279,9$ & $1.052,35$ \\
\hline & Penerimaan ( $R p$ ) & $10.239 .000,0$ & $8.418 .823,53$ \\
\hline & Pendapatan bersih ( $R p)$ & $2.857,740,6$ & $2.146 .643,30$ \\
\hline
\end{tabular}

Sumber data: Analisis data primer th. 2017

usahatani budidaya jamur tiram dengan mediamenggunakan nutrisi dedak yaitu sebesar Rp 6.272.180,23. Secara perhitungan ekonomi, biaya produksi usaha budidaya jamur tiram putih dengan media menggunakan nutrisi dedak lebih rendah dari pada media menggunakan nutrisi tepung jagung. Hal ini dikarenakan harga $1 \mathrm{~kg}$ tepung jagung sebesar Rp 4.500,- sedangkan dedak sebesar Rp 3.000,-.

\section{Produksi dan Penerimaan}

Rata-rata produksi pada usahatani budidaya jamur tiram dengan media menggunakan nutrisi tepung jagung menghasilkan jamur tiram segar sebanyak 1.279,9 kilogram dan usahatani budidaya hasil yang lebih maksimal dikarenakan kadar jamur tiram dengan media menggunakan nutrisi dedak sebesar 1.052,35 kilogram. Harga jamur tiram segar Rp 8.000,-/kg sehingga Rata-rata penerimaan usahatani budidaya jamur tiram dengan media menggunakan nutrisi tepung jagung sebesar Rp. 10.239.000,0 dan usahatani budidaya jamur tiram dengan mediamenggunakan nutrisi dedak sebesar Rp. 8.418.823,53, artinya usahatani budidaya jamur tiram dengan mediamenggunakan nutrisi tepung jagung lebih tinggi dibandingkan dengan usahatani budidaya jamur tiram dengan mediamenggunakan nutrisi dedak.

Hal ini berarti usahatani budidaya jamur tiram dengan media menggunakan nutrisi tepung jagung mampu memberikan karbohidrat media ini lebih banyak 
dibandingkan dengan menggunakan nutrisi dedak.

\section{Pendapatan Bersih}

Pendapatan bersih merupakan selisih antara nilai pendapatan kotordengan besarnya nilai biaya produksi. Pendapatan bersih merupakan imbalan yang diterima dari pengelolaan usaha (Mubyarto,1997).Ratarata pendapatan per periode yang diterima petani dengan usahatani budidaya jamur tiram dengan media menggunakan nutrisi tepung jagung sebesar $R p$ 2.857,740,6diperoleh dari penerimaan sebesar $\mathrm{Rp} 10.239 .000,0$ dikurangi biaya produksi sebesar $\mathrm{Rp}$ 7.381.259,4 dan usahatani budidaya jamur tiram dengan smedia menggunakan nutrisi dedak sebesar Rp 2.146.643,30 diperoleh dari penerimaan sebesar $\mathrm{Rp}$ 8.418.823,53 dikurangi biaya produksi sebesar Rp 6.272.180,23 artinya usahatani budidaya jamur tiram dengan mediamenggunakan nutrisi tepung jagung lebih menguntungkan dibanding media menggunakan nutrisi dedak.

\section{Analisis Kelayakan Usahatani Budidaya Jamur Tiram}

Perhitungan tentang kelayakan usahatani budidaya jamur tiram dengan media menggunakan nutrisi tepung jagung dan budidaya jamur tiram dengan media menggunakan nutrisi dedak dapat di lihat pada tabel 2 .

Tabel 2. Analisis Kelayakan Usahatani Budidaya Jamur Tiram di Kecamatan Limpung, Kabupaten Batang.

\begin{tabular}{clcc}
\hline No & \multicolumn{1}{c}{ Uraian } & Tepung jagung & Dedak \\
\hline 1. & RCR & 1,39 & 1,34 \\
2. & BEP $(\mathrm{Q})(\mathrm{kg})$ & 922,66 & 784,02 \\
& Produksi riil $(\mathrm{kg})$ & $1.279,9$ & $1.052,35$ \\
& Selisih $(\mathrm{kg})$ & 357,24 & 268,33 \\
3. & BEP $(\mathrm{Rp})(\mathrm{Rp})$ & $5.767,17$ & $5.960,15$ \\
& Harga satuan riil di pasar & 8000 & 8000 \\
& Selisih (Rp) & $2.232,83$ & $2.039,9$ \\
4. & ROI & $0,39 \%$ & $0,34 \%$ \\
\hline
\end{tabular}

Sumber data: Data primer diolah tahun 2017

\section{RCR ( Revenue Cost Ratio )}

Hasil penelitian menunjukkan rata-rata RCR pada usahatani budidaya jamur tiram dengan medianutrisi tepung jagung sebesar 1,39> 1 artinya setiap pengeluaran biaya sebesar 1 satuan produksi akan memberikan penerimaan sebesar 1,39 satuan atau jika ada pengeluaran biaya produksi sebesar $\mathrm{Rp}$. 1.000,- akan memberikan penerimaan sebesar Rp. 1.390,- kepada petani jamur tiram. Berdasarkan nilai uji kelayakan usaha jika nilai RCR lebih besar daripada 1, maka usahatani tersebut menguntungkan dan layak untuk di lanjutkan. Nilai RCR sebesar 1,39 tersebut bisa dicapai karena produksi yang dihasilkan rata-rata sebesar $1.279,9 \mathrm{~kg}$ dan

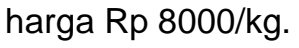

RCR pada usahatani budidaya jamur tiram dengan medianutrisi dedak sebesar $1,34>1$ artinya setiap pengeluaran biaya produksi sebesar 1 satuan produksi akan memberikan penerimaan sebesar 1,34 atau jika ada pengeluaran biaya produksi sebesar Rp. 1.000,- akan memberikan penerimaan sebesar Rp. 1.340,-. Berdasarkan nilai uji kelayakan usaha jikanilai RCR lebih besar daripada 1, maka usahatani tersebut menguntungkan dan layak diusahakan. Nilai RCR sebesar 1,34 tersebut bisa dicapai karena produksi yang dihasilkan rata-rata sebesar 1.052,35 kg dan harga Rp 8000/kg.

Rata-rata RCR pada usahatani budidaya jamur tiram dengan media menggunakan nutrisi tepung jagung adalah sebesar 1,39 dandengan media yang menggunakan nutrisi dedak sebesar1,34, sehingga usahatani budidaya jamur tiram dengan mediamenggunakan tambahan nutrisi 
tepung jagung atau dedak, layak untuk diusahakan dan dilaksanakan. Tetapi usaha tani budidaya jamur tiram dengan mediamenggunakan nutrisi tepung jagung mempunyai nilai kelayakan lebih tinggi dari pada usaha tani budidaya jamur tiram dengan media menggunakan nutrisi dedak.

\section{BEP (Break Even Point) BEP Produksi}

BEP produksi untuk mengetahui jumlah produksi minimal agar titik impas atau titik balik modal tercapai dalam satuan kilogram. BEP produksi budidaya jamur tiram dengan mediamenggunakan nutrisi tepung jagung sebesar $922,66 \mathrm{~kg}$. Nilai BEP produksi 922,66 adalah batas pokok jumlah produksi yang harus dicapai oleh petani artinya jika jumlah produksi usahatani budidaya jamur tiram lebih besar dari 922,66 maka usaha ini mengalami keuntungan, jika jumlah produksi usahatani budidaya jamur lebih kecil dari 922,66 maka usaha ini mendapatkan kerugian, pada kenyataanya poduksi jamur segar sebesar $1.279,9 \mathrm{~kg}$ lebih besar dari nilai BEP produksi 922,66maka terdapat keuntungan yaitu sebesar $357,24 \mathrm{~kg}$.

Nilai BEP produksi budidaya jamur tiram dengan medianutrisi dedak sebesar $784,02 \mathrm{~kg}$. Nilai BEP produksi 784,02 adalah batas pokok jumlah produksi yang harus dicapai oleh petani artinya jika jumlah produksi usahatani budidaya jamur tiram lebih besar dari $784,02 \mathrm{~kg}$ maka usaha ini mengalami keuntungan, jika jumlah produksi usahatani budidaya jamur lebih kecil dari 784,02 kg maka usaha ini mendapatkan kerugian, pada kenyataanya produksi jamur segar sebesar $1.052,35 \mathrm{~kg}$ lebih besar dari Nilai BEP produksi 784,02 kgberarti terdapat keuntungan yaitu sebesar268,33 kg.

Besaran jumlah produksi jamur tiram segar pada usahatani budidaya jamur tiram baik media nutrisi tepung jagungmaupun nutrisi dedak, jumlah produksi nyata lebih besar daripada jumlah pada BEP produksi masing - masing nutrisi, hal ini menunjukkan bahwa usahatani budidaya jamur tiram dengan media nutrisitepung jagungdengan media nutrisi dedak menguntungkan dan layak diusahakan. Usaha budidaya jamur tiram lebih layak jika menggunakan tepung jagung terbukti dari nilai keuntungan jumlah produksi 357,24 lebih besar dari pada menggunakan dedak hanya menghasilkan keuntungan jumlah produksi 268,33.

\section{BEP harga}

BEP harga digunakan untuk mengetahui harga minimal yang akan ditawarkan agar titik balik modal tercapai. Nilai BEP harga budidaya jamur tiram dengan medianutrisi tepung jagung sebesar Rp. $5.767,17 y a n g$ artinya jika harga jamur per $1 \mathrm{~kg}$ lebih kecil dari $\mathrm{Rp} 5.767,17$ / kg maka usahatani jamur tiram dengan menggunakan nutrisi tepung jagung akan mengalami kerugian, dan jika harga per $1 \mathrm{~kg}$ jamur tiram segar lebih dari Rp5.767,17 / kg maka usaha ini akan mendapatkan keuntungan, Harga per $1 \mathrm{~kg}$ jamur tiram segar dipasar yaitu Rp. 8000 ,-dari petani kepada pedagang / bakul terdapat selisih harga sebesar Rp. 2.232,83

BEP harga budidaya jamur tiram media nutrisi dedak sebesar Rp 5.960,15, artinya jika harga jamur per $1 \mathrm{~kg}$ lebih kecil dari $\mathrm{Rp}$ $5.960,15$ / kg maka usahatani jamur tiram dengan menggunakan nutrisi dedak akan mengalami kerugian, dan jika harga per $1 \mathrm{~kg}$ jamur tiram segar lebih dari Rp5.960,15 / kg maka usaha ini akan mendapatkan keuntungan, Harga per $1 \mathrm{~kg}$ jamur tiram segar dipasar yaitu Rp. 8000,-. Jadi terdapat selisih harga satuan sebesar Rp. 2.039,9. Perhitungan BEP Harga budidaya jamur tiram dengan media menggunakan nutrisi tepung jagung maupun nutrisi dedak lebih rendah dari pada harga budidaya jamur tiram segar dipasaran, ini menunjukkan bahwa usahatani budidaya jamur tiram pada penelitian ini mengun-tungkan dan layak untuk di usahakan. Akan tetapi secara perhitungan media yang menggunakan nutrisi tepung jaung jauh lebih tinggi keuntunganya yaitu sebesar Rp 2.232,83 dari pada menggunakan nutrisi dedak yaitu sebesar Rp 2.039,9. 


\section{ROI ( return of investmen )}

ROI Budidaya jamur tiram dengan medianutrisi tepung jagung sebesar 0,39\% sedangkan medianutrisi dedak sebesar $0,34 \%$. Apabila usaha budidaya jamur tiram ini menggunakan modal dari Bank BRI dengan bunga bank BRI yang berlaku saat penelitian sebesar $10,8 \%$ pertahun atau $0,9 \%$ per bulan maka usaha ini layak diusahakansesuai kriteria kelayakan yaitu jika bunga Bank lebih besar dari pada nilai ROI maka usaha tersebut layak diusahakan jika menggunakan pinjaman modal dari Bank. Nilai ROI bernilai positif menunjukkan bahwa usaha ini menguntungkan. Nilai ROI budidaya jamur tiram dengan media nutrisi tepung jagung lebih besar dibanding ROI budidaya jamur tiram dengan medianutrisi dedak, maka usaha tani budidaya jamur tiram dengan medianutrisi tepung jagung lebih tinggi nilai kelayakannya untuk diusahakan.

Berdasarkan ketiga kelayakan diatas pada petani budidaya jamur tiram dengan medianutrisi tepung jagung dan petani budidaya jamur tiram dengan medianutrisi dedak layak diusahakan. Tetapi nilai kelayakanya lebih tinggi jika menggunakan media nutrisi tepung jagung dari pada menggunakan nutrisi dedak.

\section{Simpulan}

Penelitian usahatani jamur tiram dengan menggunakan media nutrisitepung jagung dan dedak dapat disimpulkan sebagai berikut:

1. Rata - rata tingkat pendapatan Usahatani jamur tirammedia menggunakan nutrisitepung jagung sebesar

Rp 2.857.740,6 dan Usahatani jamur tiram media menggunakan nutrisidedak sebesar Rp 2.146.643,-

2. Usahatani jamur tirammedia menggunakan nutrisitepung jagung di Kecamatan Limpung Kabupaten Batang layak untuk diusahakan.

3. Terdapat perbedaan pendapatan antara usahatani jamur tiram yang menggunakan media nutrisitepung jagung dan media nutrisi dedak di Kecamatan Limpung Kabupaten Batang dan lebih baik jika media baglog jamur menggunakan nutrisi tepung jagung.

\section{DAFTAR PUSTAKA}

Alex, S. M. 2011. Untung Besar Budi Daya Aneka Jamur. Pustaka Baru Press, Yogyakarta.

Karim, Abdul. 2010. Karakteristik pertumbuhan dan produksi jamur Tiram Putih. Skripsi, Jurusan Budidaya Pertanian Faperta Universitas, Riau.

Mubyarto, 1994. Pengantar Ekonomi Pertanian, Edisi 3, LP3ES, Jakarta Nicholson. 2001. Teori Ekonomi Mikro Prinsip Dasar dan Pengembangannya. PT Raja Grafindo Persada. Jakarta

Piryadi, Triono Untung. 2013. Bisnis Jamur Tiram. Agromedia Pustaka. Jakarta. 